\title{
A Literature Review of High Quality Development in Manufacturing
}

\author{
Xingle Teng \\ Business School, Shandong University of Technology \\ Zibo, China \\ Email: 1751205977 [AT] qq.com
}

\begin{abstract}
China's economy has entered a new stage of development. High-quality manufacturing development is an important part of the high-quality development of the Chinese economy, and promoting high-quality manufacturing development is a strategic requirement in response to changes in the internal and external situation. This paper reviews and summarizes the important achievements of the research on the high quality development of manufacturing industry in recent years from four perspectives: connotation, path, evaluation system and evaluation of the high quality development of regional manufacturing industry, and points out the shortcomings of the current research.
\end{abstract}

Keywords--- Manufacturing, High quality development, Evaluation system

\section{INTRODUCTION}

It is the only way to promote the upgrading and transformation of manufacturing industry to adapt to the changes of China's economic development stage and move towards a new stage of industrialization. High-quality manufacturing development is also an important part of high-quality economic development. At present, there are many literatures on the high-quality development of manufacturing industry. We have made a simple summary through systematic combing.

\section{WORK BASE}

(1)Research on the connotation of high quality development in manufacturing industry

Different scholars put forward different views on the connotation of high-quality development of manufacturing industry. Professor Zhu Qigui (2018) summarized the connotation of high-quality development from a macro perspective as the development of implementing green, sharing and other new development concepts. Huang Hanquan (2019) believes that the scientific connotation of high-quality development of manufacturing industry should be elaborated from six dimensions: quality, efficiency, power, region, ecology and openness. Xu Zhaoyuan (2019) pointed out that the highquality development of manufacturing industry should be summarized from four aspects: improving product quality, clean and efficient production process, good enterprise benefits and increasing international competitiveness.

(2)Research on the high quality development path of manufacturing industry

Huang Qunhui (2018) proposed that we must establish a good innovation ecosystem and strive to improve the technological innovation ability of manufacturing industry by establishing a high quality view, so as to promote the highquality development of manufacturing industry in China. Xin Guobin (2018) pointed out at the annual meeting of China's economy that to achieve high-quality development of China's manufacturing industry, the key points should be to make up for the shortcomings and weaknesses in key areas, optimize the innovation ecology of manufacturing industry, cultivate and develop advanced manufacturing clusters, and promote industrial integration. Miao Wei (2019) pointed out that the high-quality development of manufacturing industry should be promoted from five aspects: improving innovation ability, optimizing industrial structure, cultivating high-quality enterprises, perfecting system environment and improving the level of opening up to the outside world. Zhang Jie (2019) pointed out that the high-quality development of China's manufacturing industry should be led by key core technology innovation. After objectively analyzing the development status of China's equipment manufacturing industry and the development trend of international intelligent manufacturing, Sunberlin (2019) believes that to achieve the high-quality and sustainable development of China's equipment manufacturing industry, it is necessary to actively build independent famous brands, vigorously develop modern manufacturing services and introduce high-tech. Lishaobo (2019) proposed to promote the high-quality development of Guizhou manufacturing industry through four aspects: big data + intelligent manufacturing, deep integration of advanced manufacturing and modern service industry, vigorously developing technological 
innovation and developing intelligent manufacturing talents training. Tengtangwei and Qu Congyi (2018) put forward that efforts should be made in strengthening innovation subjects, building innovation network and training innovative talents by drawing lessons from the development experience of California manufacturing industry in the United States, so as to promote the high-quality development of Shanghai manufacturing industry.

\section{(3)Research on the evaluation system of high quality development of manufacturing industry}

The National Bureau of Statistics of China began to explore the establishment of some relevant indicators a few years ago, such as China Innovation Index Research Report, which measures and evaluates China's technological innovation ability from four dimensions of innovation environment, innovation input, innovation output and innovation effectiveness. In addition, the National Bureau of Statistics also for the economic development of our country's green released the report "China's green development index, constructed including the green economic growth, resources and environment carrying potential and government support three aspects of first-level indicators, then points the provincial level and city level has a number of secondary and tertiary indicators. In 2017, the National Bureau of Statistics established the New Kinetic Forces Index, which measures industrial development, covering six aspects, including knowledge capability, economic vitality and digital economy. But these indicator systems only capture some aspects of quality development.

Jiangsu Province and CIDI Think Tankk are the earlier provinces and institutions in China to study the high quality development index system of manufacturing industry. Among them, the General Office of the Jiangsu Provincial Governmen and Jiangsu Information Technology Commission established a comprehensive evaluation system reflecting high-quality development in 2017. In July 2018, CCID Think Tank initially constructed a manufacturing high-quality development index system with 27 specific indicators, including seven aspects of technological innovation, structural upgrading, speed growth, factor efficiency, brand building, integrated development and green manufacturing.

Chen Sian, Wang Jianguo, Du Tianrui et al. (2018) constructed an index evaluation system for high-quality development level of manufacturing industry from five aspects, including quality and benefit, innovation ability, green and low-carbon, international competitiveness and social contribution. After comparing Ningbo with 10 strong manufacturing cities such as Shanghai, Suzhou, Tianjin, Dalian and Qingdao, it is found that Ningbo manufacturing industry is not competitive in terms of quality and benefit, scientific and technological innovation and social contribution. $\mathrm{Xu}$ Weihua (2019) established a high-quality development evaluation system for manufacturing industry in Henan Province covering 20 indicators in five aspects, namely transformation development, innovation development, integration development, green development and enterprise development, on the basis of combing relevant domestic researches on the construction of high-quality development of manufacturing industry in recent years.

(4)Study on the high quality development level of regional manufacturing industry

In order to achieve the goal of high-quality manufacturing development, some Chinese scholars have studied the high-quality development of manufacturing industry in some provinces and cities in the unit of region.Lv Yongquan (2018), Chen Lili (2018), Wang Zhongya (2018) and Cheng Wen (2019) respectively summarized and analyzed the highquality development of the manufacturing industry in Guangxi Province and Zhejiang Province, and the advanced manufacturing industry in Henan Province and Tianjin City. Lv Tie and Liu Dan (2019) summarized the development process of China's manufacturing industry in the past 40 years of reform and opening up, and drew the following conclusions: China has a large scale advantage, labor productivity continues to grow, and there are significant technological innovation achievements; However, the manufacturing industry has not yet formed a quality and benefit advantage nationwide, lacks core competitiveness in the international market, lacks innovation capacity, and is at a disadvantage in the global pattern of industrial and technological innovation.

\section{CONSTRUCTION OBJECT}

Through literature review, we find that:(1)the high-quality development of manufacturing industry in the new era is a relatively new content. Most of the current research focuses on the definition of connotation, the carding of development path, the construction of evaluation system and empirical measurement.(2)The construction and measurement of the comprehensive evaluation system for high quality development of manufacturing industry need to be improved. At present, the index system that scholars try to establish has its own characteristics, but there are also some problems: the index system can not reflect the characteristics of the new era; Process and result indicators are mixed; Repeat the same index; Some indicators are difficult to measure.(3)The research on the measurement of high quality development level of regional manufacturing industry is relatively few. The research ideas of high-quality development of regional manufacturing industry focus on the derivation of existing problems from the current situation of regional development, and put forward solutions and suggestions according to the actual situation. Few articles have measured the development degree of high quality manufacturing industry. 


\section{REFERENCES}

[1] Zhu Qigui . Establishing an index system to promote high-quality development [N]. Wenhui Daily, 2018-02-06 (012)

[2] Huang Hanquan. Breakthrough Difficulties and System to Promote High-quality Development of Manufacturing Industry [N]. Economic Daily, 2019-03-14 (016)

[3] Xu Weihua. Construction of high quality manufacturing development index system in major grain producing areas of China: A case study of Henan Province [J].China's Prices, 2019 (02) : 44-46

[4] Zhang Wenhui . Research on Quality Development of Manufacturing Industry in China [J]. Industrial Economy Review, 2018, v.05; No. 27 (03) : 5-10

[5] Yin Xingmin . Five dimensions of a high quality development indicator system [EB/OL].WenhuiDaily.2017 http://ex.Cssn.cn/glx/glx_xzlt/201802/t20180206_3841995.html

[6] Research Group of National Bureau of Statistics. China has initially established a statistical system reflecting new drivers and new industries[EB/OL].The Xinhua News Agency.2017 . http://jjckb.xinhuanet.com/201709/07/c_136592072.html

[7] Lv Tie, Liu Dan. Quality development of manufacturing industry: gap, problems and measures [J]. Study \& Exploration, 2019 (01) : 111-117

[8] Teng Tangwei, Qu Congyi. A study on the development of manufacturing industry in Shanghai [J]. Science in China, 2018 (04) : 21-29

[9] Lv Yongquan. On promoting the high quality development of manufacturing industry in Guangxi [J]. Economic and Social Observation, 2018,16 (05) : 1-7

[10] Chen wen. Enhancing industrial technology support to boost the high quality development of advanced manufacturing industry in Tianjin [J]. Industrial Innovation Research, 2018 (12) : 11-13 